\title{
Antisocial Behavior
}

National Cancer Institute

\section{Source}

National Cancer Institute. Antisocial Behavior. NCI Thesaurus. Code C94296.

A deliberate pattern of behavior that demonstrates both willful aggression toward other people and an intentional disregard for the common, current norms of social conduct. 